\title{
ANALYSIS OF THE PROCESSING SEQUENCE ON AIRFRAME STRUCTURES MACHING DEFORMATION
}

\author{
Guichu Ding ${ }^{1}$, Tao Zhang ${ }^{1}$, Hongwei Li ${ }^{2}$, Xiaoming Huang 2 \\ 1 Mechanical Engineering Department, Tianjin Vocational technology Normal University, \\ Tianjin 300222, China \\ 2 Mechatronics Engineering Department, Binzhou University, Binzhou 256603, China
}

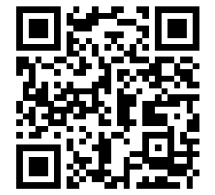

DOI: https://doi.org/10.29121/ijetmr.v7.i6.2020.683

Article Citation: Guichu Ding, Tao Zhang, Hongwei Li, and Xiaoming Huang. (2020). ANALYSIS OF THE PROCESSING SEQUENCE ON AIRFRAME STRUCTURES MACHING DEFORMATION. International Journal of Engineering Technologies and Management Research, 7(6), 110.

https://doi.org/10.29121/ijetmr.v7 .i6.2020.683

Published Date: 10 June 2020

Keywords:

Initial Residual Stress

Processing Strategy

Processing Deformation

Finite Element

Block Processing Sequence

\section{ABSTRACT}

In order to reveal the influence of different processing procedures on the machining deformation of the whole structure of aviation frame type, a prediction model for the deformation of frame type integral structure caused by initial residual stress was established based on finite element. According to the deformation law of frame parts caused by initial stress of blank, the deformation of whole structure parts based on aviation frame is minimized. The influence of processing process on deformation of frame structure is studied. The results show that when removing the frame material, the deformation of the workpiece can be slowed down by first removing the area with large deformation and relatively concentrated material. And symmetrical removal of the frame material can also slow the deformation of the workpiece.

\section{INTRODUCTION}

With the rapid development of modern aviation industry, the use of aircraft structural parts has put forward higher requirements, and more and more integral structural parts have been adopted. However, the problem of deformation of integral structural parts has been puzzling the aviation manufacturing industry. European and American countries have long been concerned about the processing deformation of aviation structural parts. Airbus has been researching since the mid-1990s. At the manufacturing level, a solution that requires only CNC personnel to do the job [1][2].

The characteristics of aviation integral structural parts mainly include large size, complex structure and many thin walls. After NC machining, it is easy to cause deformation [3]. Due to the deformation of the whole structural parts, the parts often fail to meet the requirements. It even increases the chance of waste products, which has a great impact on the progress of production and the economic benefits of the enterprise. Although there are many factors that lead to the deformation of the whole structural parts, the analysis of a series of research results and the field investigation shows that the initial residual stress is the main factor causing the deformation of the whole structural parts [4]. At present, most of the whole structure of aviation is obtained by high-speed cutting. Therefore, relative to

(C) 2020 The Author(s). This is an open access article distributed under the terms of the Creative Commons Attribution License, which permits unrestricted use, distribution, and reproduction in any medium, provided the original author and source are credited. 
the effect of initial residual stress on machining deformation, the effect of cutting heat and cutting force on deformation can be neglected。Huang[5] studied the deformation law of the whole structure of aviation and carried out related experiments in base the initial residual stress of the blank and the finite element simulation. After comparative analysis, it is concluded that the influence of initial residual stress on deformation of structural parts is over $90 \%$ under high-speed cutting, American scholar S. Nervi[6] takes into account the initial state of the blank and the position of the component shape. And the final deformation of the parts is predicted. Wu Yunxin[7] established a three-dimensional finite element model for predicting the milling deformation of aviation aluminum alloy thin wall parts. And experimental results show that the proposed finite element model can effectively predict machining deformation of aluminum alloy thin-walled parts.

Airframe parts are an important part of the aviation structure. The main features of the frame parts are the following: the shape is relatively large, its bearing force is also relatively large; the box is numerous and complex; thin-walled structure, processing easy deformation; divided into single-sided frame and double-sided frame, its structure is basically symmetrical up and down or left and right. Although the shape of the frame structure is different, but in fact, there are regular rules to follow, the box is mainly divided into one-sided and two-sided, symmetrical and asymmetrical, in processing methods and processing technology is basically the same[8].

The research object of this paper is 7050-T7451 aluminum alloy single-sided frame whole structure. Based on the finite element (finite element) Abaqus, a predictive model for the deformation of frame-like structural parts caused by residual stress was established. The deformation law of workpiece caused by initial stress of blank is analyzed, and the influence of different frame processing technology on the deformation of workpiece is studied.

\section{MODEL OF FRAME CLASS STRUCTURE}

The frame structure is complex in structure, and most of the frames are irregular. Therefore, it is obviously unrealistic to build a model exactly like the actual structure. It is necessary to simplify the frame structure and ignore some structural features which have little influence on the processing deformation. For example: process hole, chamfer, etc. Figure 1 is a simplified model of a type of civil aircraft frame. Its peripheral contour geometric size is $1000 \mathrm{~mm} \times 1000 \mathrm{~mm} \times 60 \mathrm{~mm}$, and the wall thickness of the workpiece is $5 \mathrm{~mm}$.

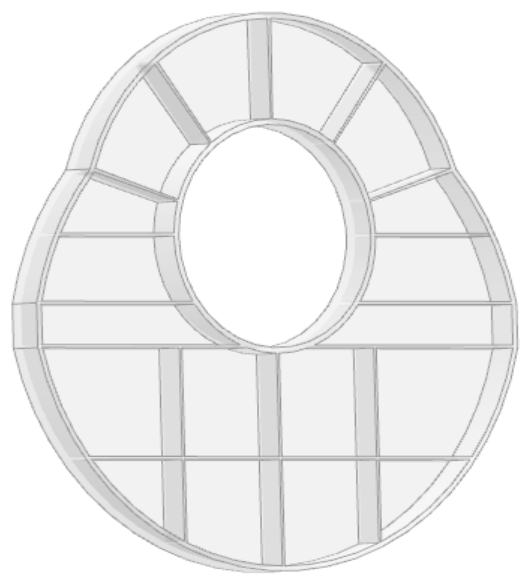

Figure 1: Simplified Single Frame Model

\section{FINITE ELEMENT MODELING FOR MACHINING DEFORMATION OF FRAME STRUCTURAL PARTS}

1) Aluminum alloy 7050-T7451 is selected as blank material, Young's modulus is $71700 \mathrm{MPa}$, Poisson's ratio is 0.33 , and the overall size of blank is $1100 \mathrm{~mm} \times 1100 \mathrm{~mm} \times 60 \mathrm{~mm}$.

Figure 2 shows the initial residual stress of the 7050-T7451 aluminum alloy pre-stretch plate produced by US Kaiser Aluminum \& Chemical Corp [10]. From figure 2, it can be seen that the residual stress change in the rolling direction (the $\mathrm{x}$-axis direction) is obviously larger than that in the transverse direction (the $y$-axis direction). With the neutral surface as the center, the residual stress in both directions is symmetrical. 


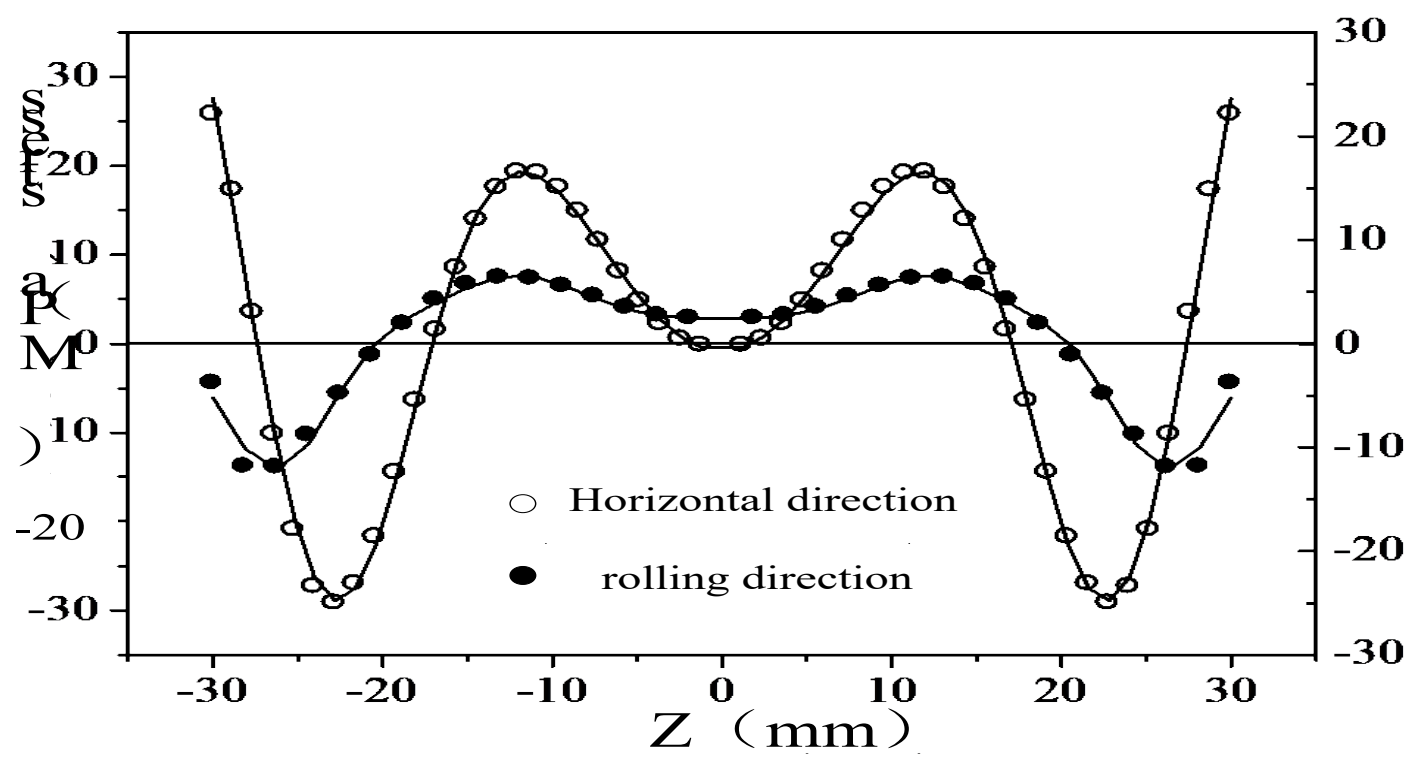

Figure 2: Initial residual stress of aluminum alloy pre-stretch plate

The method of applying initial stress to finite element model is to discretize the initial stress of aluminum alloy sheet. The discretized initial stress is then applied layer by layer to the workpiece of the partitioned mesh. In order to improve the accuracy and reduce the error caused by the discretization of the stress field, the multi-peak Gaussian curve is fitted according to the initial stress distribution characteristics of the blank [7]. The fitting formula is:

$$
\begin{aligned}
& \sigma_{x}=70.74-71.51 e^{-0.00393 Z^{2}}-\sum_{i=1}^{2} 90.63 e^{-0.017\left[Z-23.18 \times(-1)^{i}\right]^{2}} \\
& \sigma_{y}=2.76-\sum_{i=1}^{2} 17.02 e^{-0.0487\left[Z-26.34 \times(-1)^{i}\right]^{2}}+\sum_{i=1}^{2} 4.944 e^{-0.0367\left[Z-12.01 \times(-1)^{i}\right]^{2}}
\end{aligned}
$$

2) Boundary Conditions and Meshing

Adopt the solid-branch constraint, that is, the constraint of 6 degrees of freedom, after processing, release the constraint. Unit type C3D8R is used in the calculation.

In the process of practical processing, the residual stress inside the workpiece is gradually released. The redistribution of residual stress forms a new equilibrium state inside the workpiece. After discretizing the initial stress of the blank, a layer is applied to the finite element model. The blank is divided into 12 layers.

3) Processing simulation

In the finite element ABQUS, the material removal is realized by using the technology of life and death unit [11] - Select the material you want to remove and calculate it as a load step in a finite element. With the removal of the material, the residual stress within the workpiece is redistributed.

\section{EFFECT OF FRAME MACHINING SEQUENCE ON PROCESSING DEFORMATION OF WORKPIECE}

Figure 3 is a finite element model that divides the area into A, B and $\mathrm{C}\left(\sum_{i=1}^{18} C_{i}\right)$. where $\mathrm{A}$ is the peripheral material to be removed, $\mathrm{B}$ is the intermediate circular hole material to be removed, and $\mathrm{C}$ is the spacer material to be removed. After processing, release its constraints and select point $\mathrm{D}$ as the fixed reference point. 


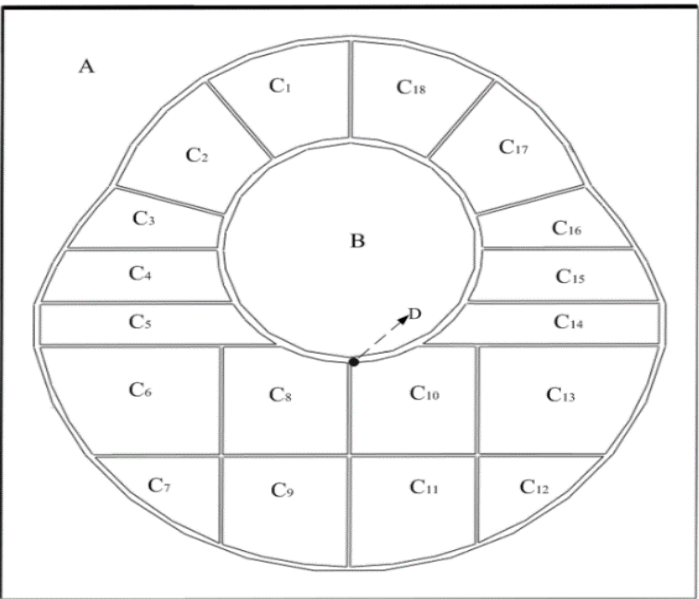

Figure 3: element model for partitioning regions

According to the processing sequence of C-B-A, the material of the spacer frame is removed first, then the material of the middle circular hole is removed, and the peripheral material is finally removed. the material removal area and the corresponding material removal rate are shown in table 1 . On this basis, this paper focuses on the effect of the removal of the bulkhead (area $\mathrm{C}$ ) sequence on the deformation of the workpiece.

Table 1: Material removal area and corresponding material removal rate

\begin{tabular}{|l|l|l|l|}
\hline Removal of areas & A & B & C \\
\hline material removal rate & $35 \%$ & $15 \%$ & $38 \%$ \\
\hline
\end{tabular}

\subsection{THE EFFECT OF THE REMOVAL SEQUENCE OF "S" AND "T" ON THE DEFORMATION OF STRUCTURAL PARTS}

As can be seen from Figure 4, the spacer area is divided into the upper and the next two parts (excluding A and B regions), of which 1,2,3,4... represents the processing order of the septum. Fig.4(a) is processed from the lower left corner Cg1 frame to the $\mathrm{Cn} 18$ frame in the order in which the Arabic numerals are processed and, in the direction, indicated by the arrow. That is, the lower area is removed first and then the upper area is removed. Fig.4(b) is processed from the Ce1 frame to the C $\mathrm{j} 8$ frame according to the sequence of processing of the marked Arabic numerals and the direction indicated by the arrow. That is to remove the upper area, and then remove the lower area. In order to facilitate the following analysis, the processing sequence of the frame in Fig. 4(a)is defined as " $S$ ", and the processing sequence of the frame in Fig. 4(b)is defined as "T".

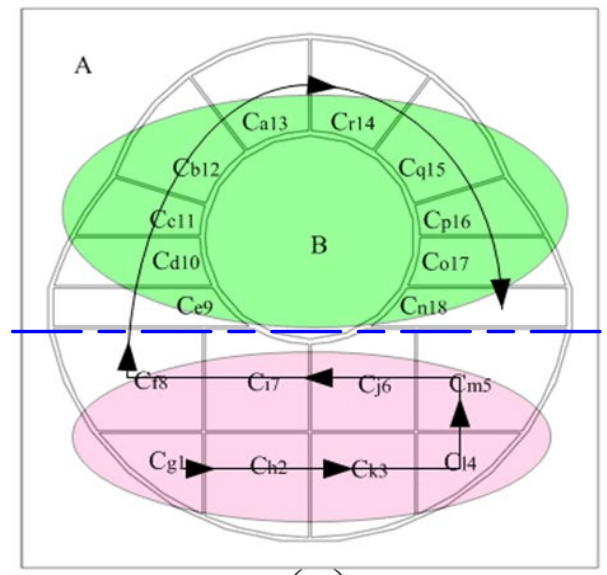

(a)

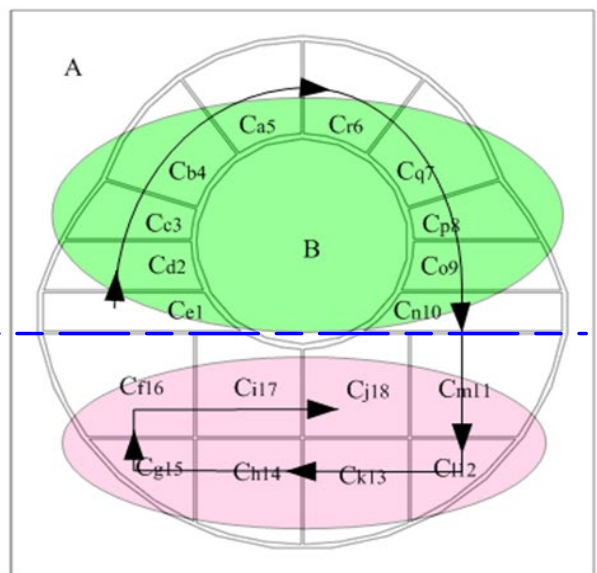

(b)

Figure 4: Processing sequence of two kinds of bulkhead 
Figure 5 is the corresponding workpiece stress diagram and deformation diagram obtained after processing according to the processing sequence of Figure 4(a). As can be seen from Figure 5(a), the maximum residual stress of the workpiece is $41.17 \mathrm{MPa}$. It can be seen from Figure 5(b) that the maximum deformation is located at the top of the workpiece and the maximum deformation is $0.985 \mathrm{~mm}$.

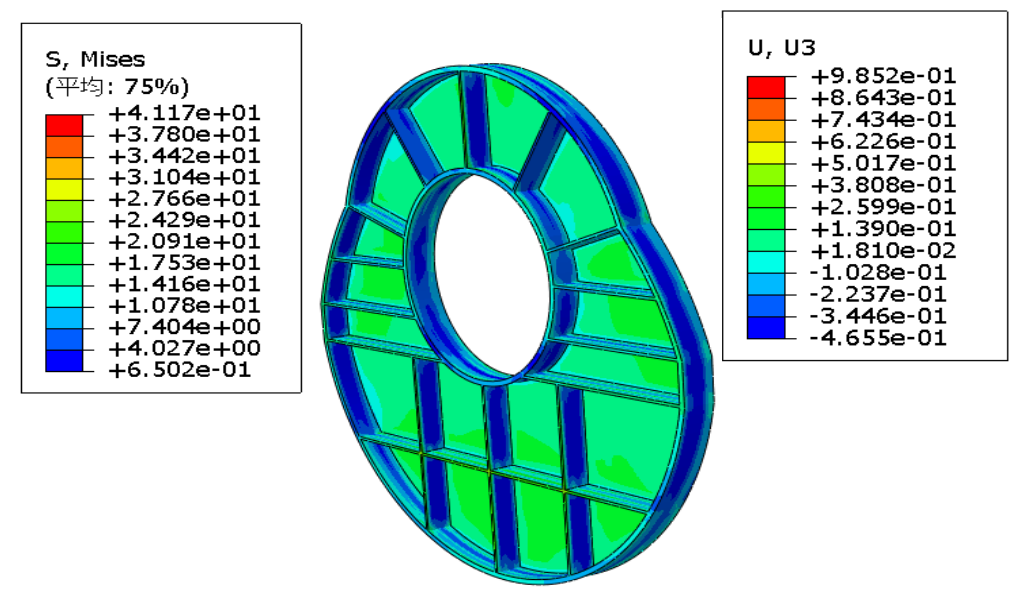

(a)

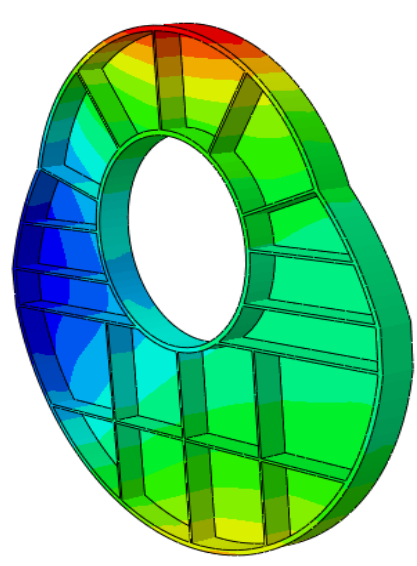

(b)

Figure 5: Stress and deformation of workpiece

Figure 6 is the corresponding workpiece stress diagram and deformation diagram obtained after processing according to the processing sequence of Figure 4(b). It can be seen from Figure 6(a) that the maximum residual stress of the workpiece is $41.17 \mathrm{MPa}$. It can be seen from Figure 6(b) that the maximum deformation is at the top of the workpiece and the maximum deformation is $1.210 \mathrm{~mm}$.

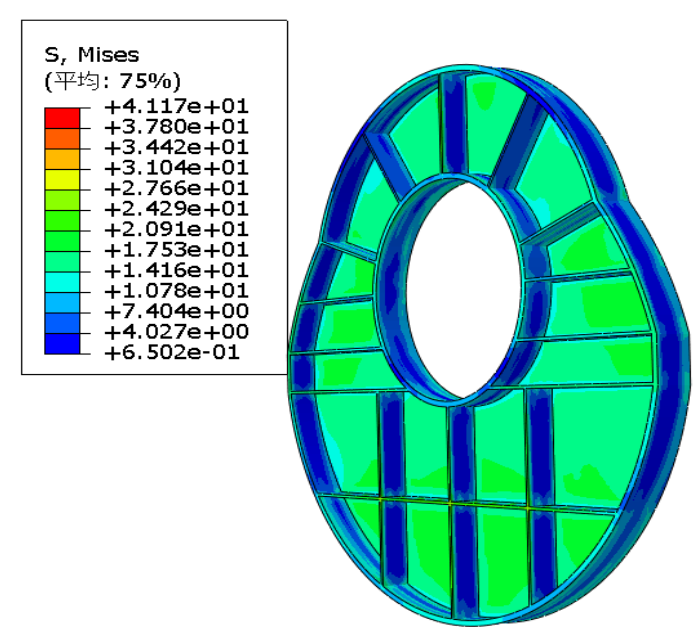

(a)
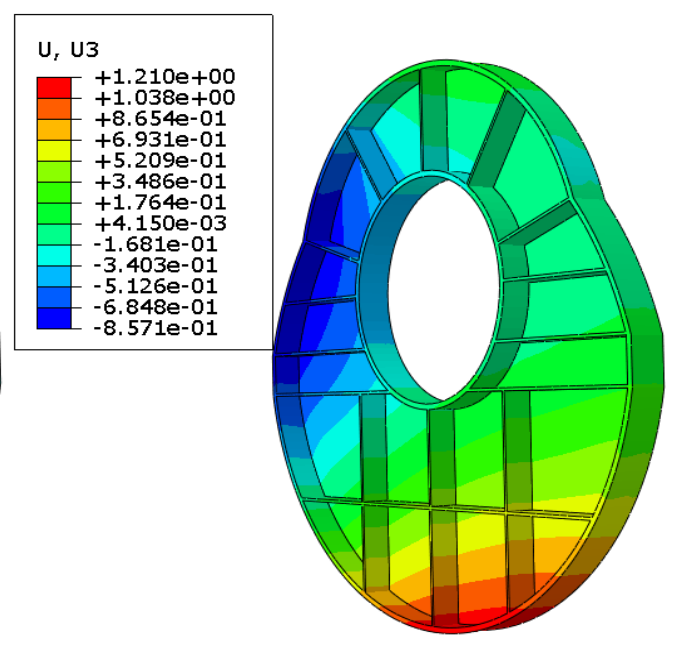

(b)

Figure 6: Stress and deformation of workpiece

According to the above analysis, there are two kinds of box removal methods:" $\mathrm{S}$ ". The workpiece deformation obtained by the box removal of the "S ". That is to remove the lower area first, and then remove the upper area, the resulting workpiece deformation is relatively small. This is due to the relatively large number of materials removed from the lower regions and their concentration in the main deformed regions. Remove the lower area first, the other areas of the workpiece can provide a relative support to slow the deformation of the workpiece. Then remove the upper region with relatively small deformation. 


\subsection{THE EFFECT OF THE REMOVAL SEQUENCE OF "U" AND "V" ON THE DEFORMATION OF STRUCTURAL PARTS}

Figure 7 is two different sequence of compartment processing, where 1,2,3,4... represents the processing order of the spacer. Figure 7(a) is processed from the $\mathrm{Cg} 1$ frame to $\mathrm{Ce} 18$ in sequence according to the sequence of processing of the marked Arabic numerals (Cg1-Cl2-Ch3-Ck4-Cf5-Cm6-Ci7-Cj8-Cn9-Co10-Cp11-Cq12-Cr13-Ca14Cb15-Cc16-Cd17-Ce18). Figure 7(b) is processed from the Cf1 frame to the Ce18 frame in the order in which the marked Arabic numerals are processed and, in the direction, indicated by the arrow. As in Figure 4 above, for the purposes of the following analysis, the sequence of frame processing in Figure 7(a) is defined here as "U" and the sequence of frame processing in Figure 7(b) is defined as "V".
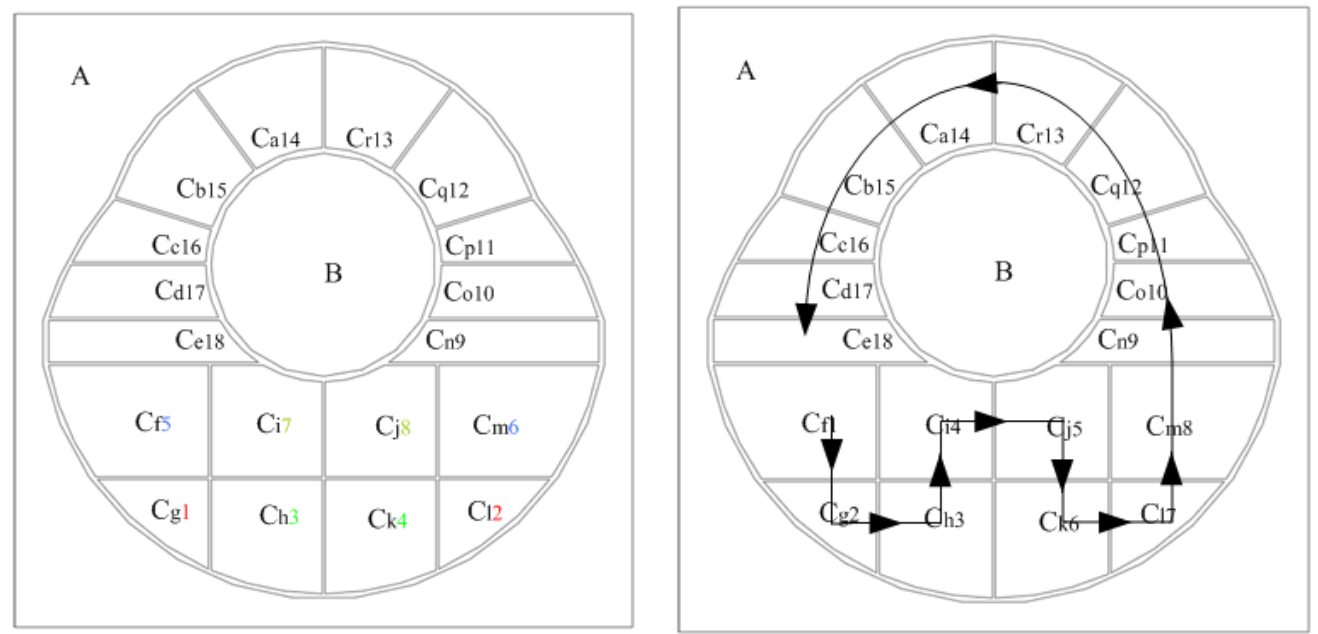

Figure 7: Processing sequence of two frames

Figure 8 is the corresponding workpiece stress diagram and deformation diagram obtained after processing according to the processing sequence of Figure 7(a). It can be seen from Figure 8(a) that the maximum residual stress of the workpiece is $41.17 \mathrm{MPa}$. It can be seen from Figure 8(b) that the maximum deformation is located at the top of the workpiece and the maximum deformation is $1.027 \mathrm{~mm}$.

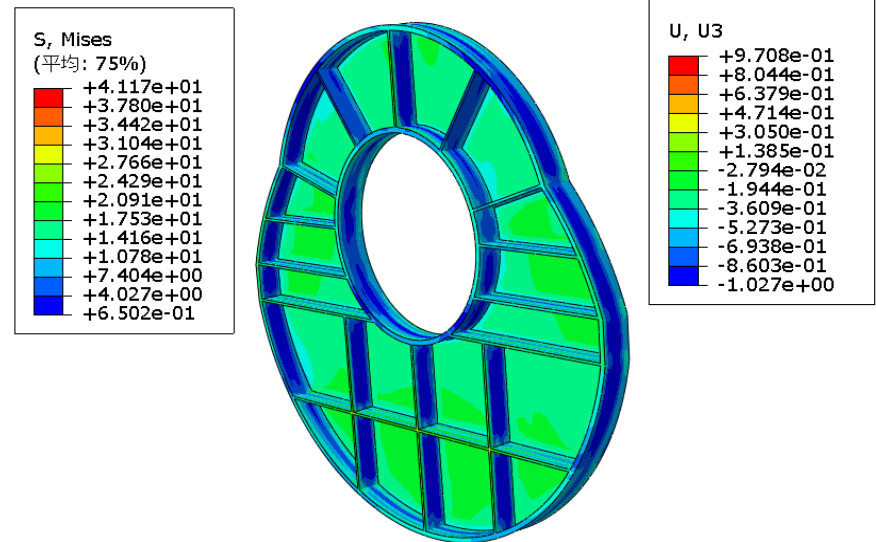

(a)

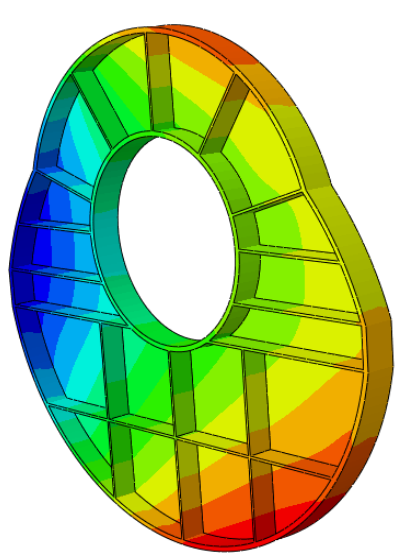

(b)

Figure 8: Stress and deformation of workpiece

Figure 9 is the corresponding workpiece stress diagram and deformation diagram obtained after processing according to the processing sequence of Figure 7(b). It can be seen from Figure 9(a) that the maximum residual stress of the workpiece is $41.17 \mathrm{MPa}$. It can be seen from Figure 9 (b) that the maximum deformation is located at the top of the workpiece and the maximum deformation is $1.145 \mathrm{~mm}$. 


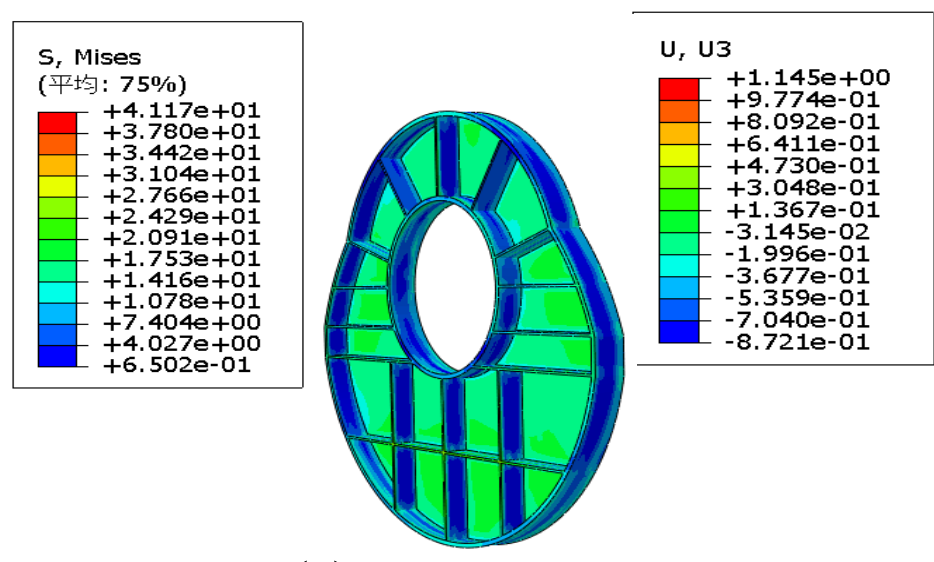

(a)
.

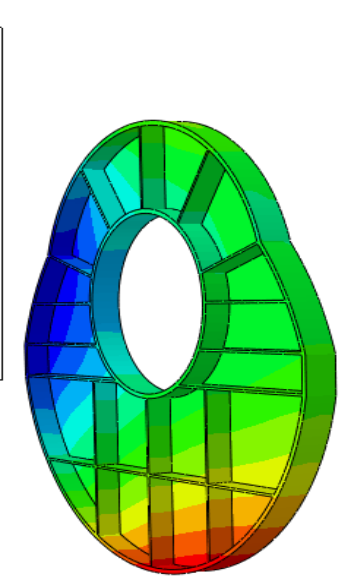

(b)

Figure 9: Stress and deformation of workpiece

According to the above analysis, there are two kinds of box removal methods:" S ". "U " has a smaller deformation of the workpiece than" $\mathrm{V}$ ". When removing the lower area first, the left and right symmetrical removal of the spacer is less deformed than the sequential removal of the spacer. This is because compared with the sequential removal of the spacer, the left and right symmetrical removal of the spacer can make the change of residual stress in the workpiece more stable, so the deformation is relatively small.

\subsection{THE EFFECT OF THE REMOVAL SEQUENCE OF "W" AND "X" ON THE DEFORMATION OF STRUCTURAL PARTS}

Figure 10 shows the processing sequence of two different removal materials. where Figure $10(a)$ is processed from the $\mathrm{Ca} 1$ frame, sequentially to the $\mathrm{Ck} 18$ frame according to the processing order of the marked Arabic numerals. Figure $10(\mathrm{a})$ is processed from the $\mathrm{Ca} 1$ frame to the $\mathrm{Ck} 18$ frame in order of processing of the marked Arabic numerals (Ca1-Cr2-Cb3-Ckq4-Ce5-Cp6-Cd7-Co8-Ce9-Cn10-Cf11-Cm12-Ci13-Cj14-Cg15-Cl16-Ch17-Ck18). That is to remove the frame symmetrically from top to bottom. Figure $10(\mathrm{~b})$ is processing from the Cg1 frame to the Cr18 frame in sequence according to the processing order of the marked Arabic numerals (Cg1-Cl2-Ch3-Ck4-Cf5-Cm6-Ci7-Cj8-Ce9Cn10-Cd11-Co12-Cc13-Cp14-Cb15-Cq16-Ca17-Cr18). That is, from the bottom to the left and right symmetrical way to remove the box. As in figure 4 above, here the sequence of box processing in Figure 10(a) is defined as "W" and the sequence of box processing in Figure 10(b) is defined as " $\mathrm{X}$ ".
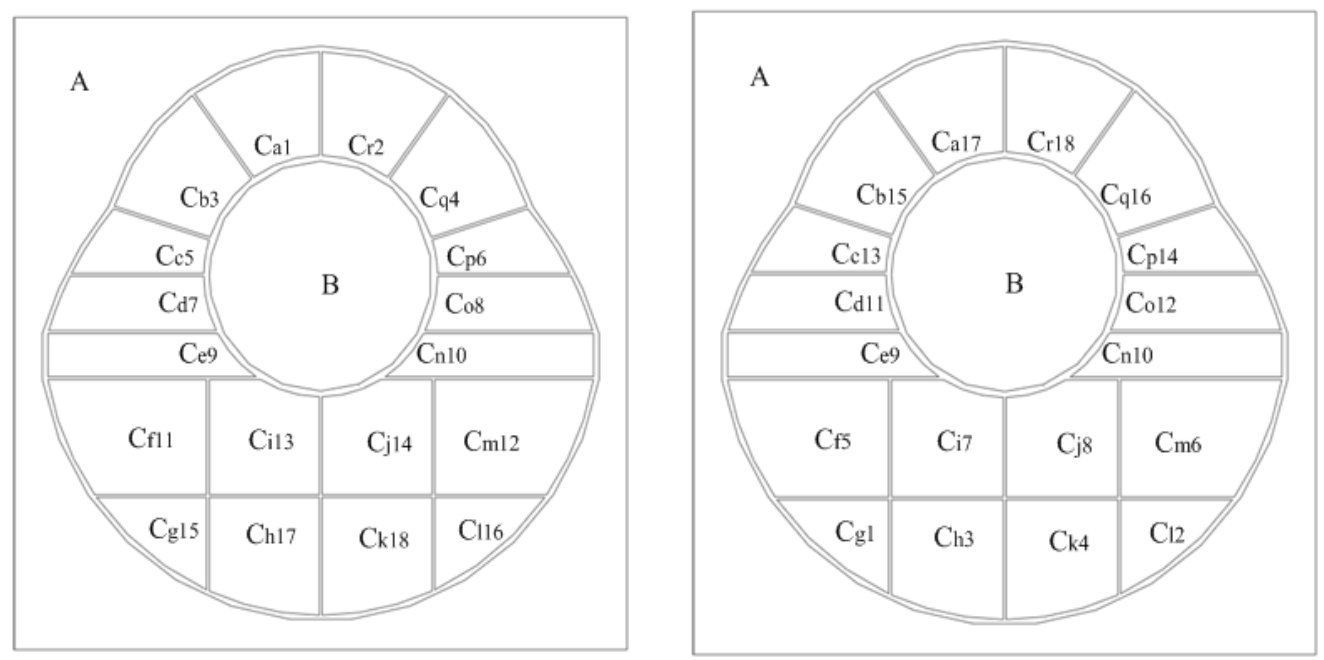

Figure 10: Two kinds of frame processing sequence diagram 
Figure 11 is the corresponding workpiece stress diagram and deformation diagram obtained after processing according to the processing sequence of Figure 10(a). It can be seen from Figure 11(a) that the maximum residual stress of the workpiece is $41.17 \mathrm{MPa}$. It can be seen from Figure 11(b) that the maximum deformation is located at the top of the workpiece and the maximum deformation is $1.215 \mathrm{~mm}$.

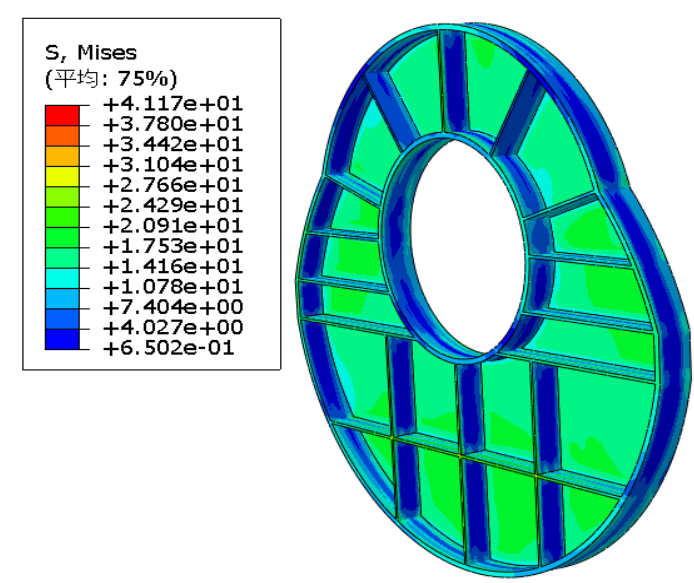

(a)
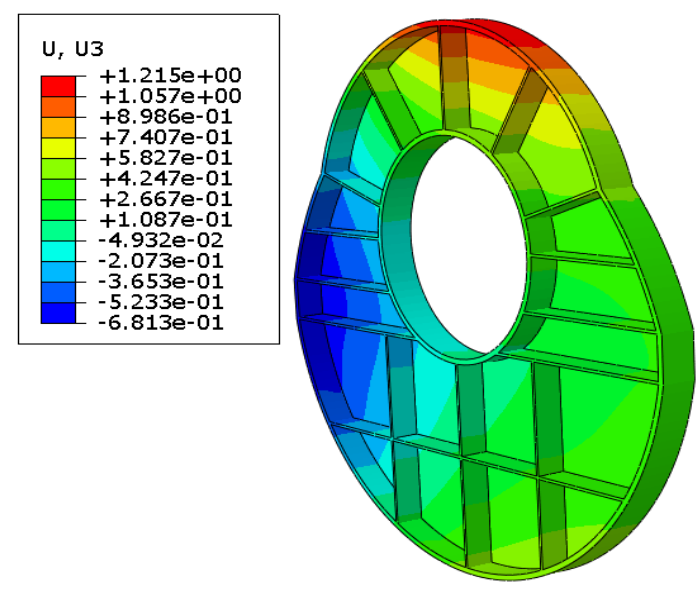

(b)

Figure 11: Stress and deformation of workpiece

Figure 12 is the corresponding workpiece stress diagram and deformation diagram obtained after processing according to the processing sequence of Figure 10(b). It can be seen from Figure 12(a) that the maximum residual stress of the workpiece is $41.17 \mathrm{MPa}$. It can be seen from Figure 12(b) that the maximum deformation is located at the top of the workpiece and the maximum deformation is $0.953 \mathrm{~mm}$.

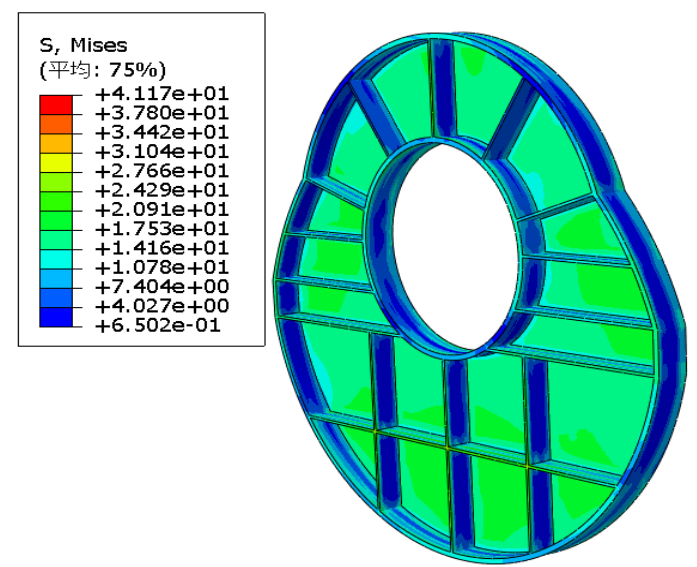

(a)

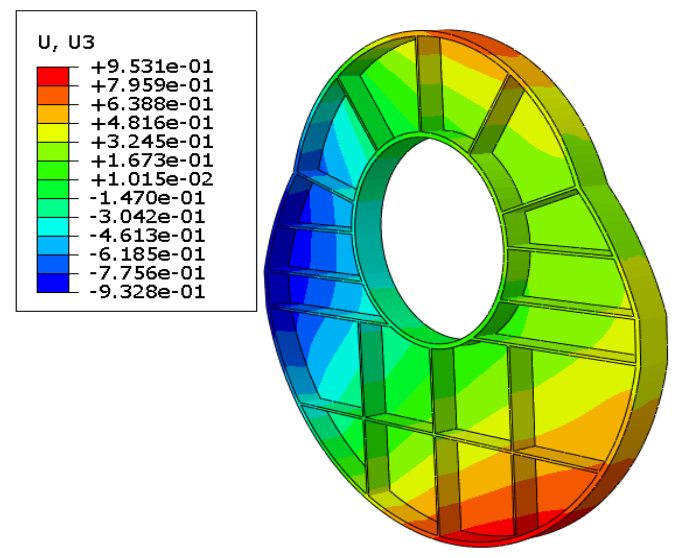

(b)

Figure 12: Stress and deformation of workpiece

According to the above analysis, "W "(Fig.10(a)) and" X "(Fig.10(b)) are two types of box removal and the "X "(fig.10(b)) is less deformed than the" W"(fig.10(a)). That is to say, the workpiece deformation obtained by removing the frame from the bottom up is relatively small. That is to remove the lower area with large deformation first, the other areas of the workpiece can provide a relative support to slow down the deformation of the workpiece; then remove the upper area with relatively small deformation.

To sum up, when removing the frame material, first remove the area where the workpiece is deformed and the material is relatively concentrated, then remove the other areas. This will slow down the deformation of the workpiece. And symmetrical removal of the frame material can also slow the deformation of the workpiece. 
In order to more accurately analyze the influence of the processing sequence of different spacers on the deformation of the workpiece, the optimal processing sequence of the spacers is found. On the basis of the C-B-A machining sequence, the numerical analysis of the workpiece was carried out for 6 different frame processing sequence. And the corresponding coordinate system is established. This can more intuitively reflect the maximum deformation of each process and easy to compare. Figure 13 shows the maximum deformation of the six different frame processing sequences.

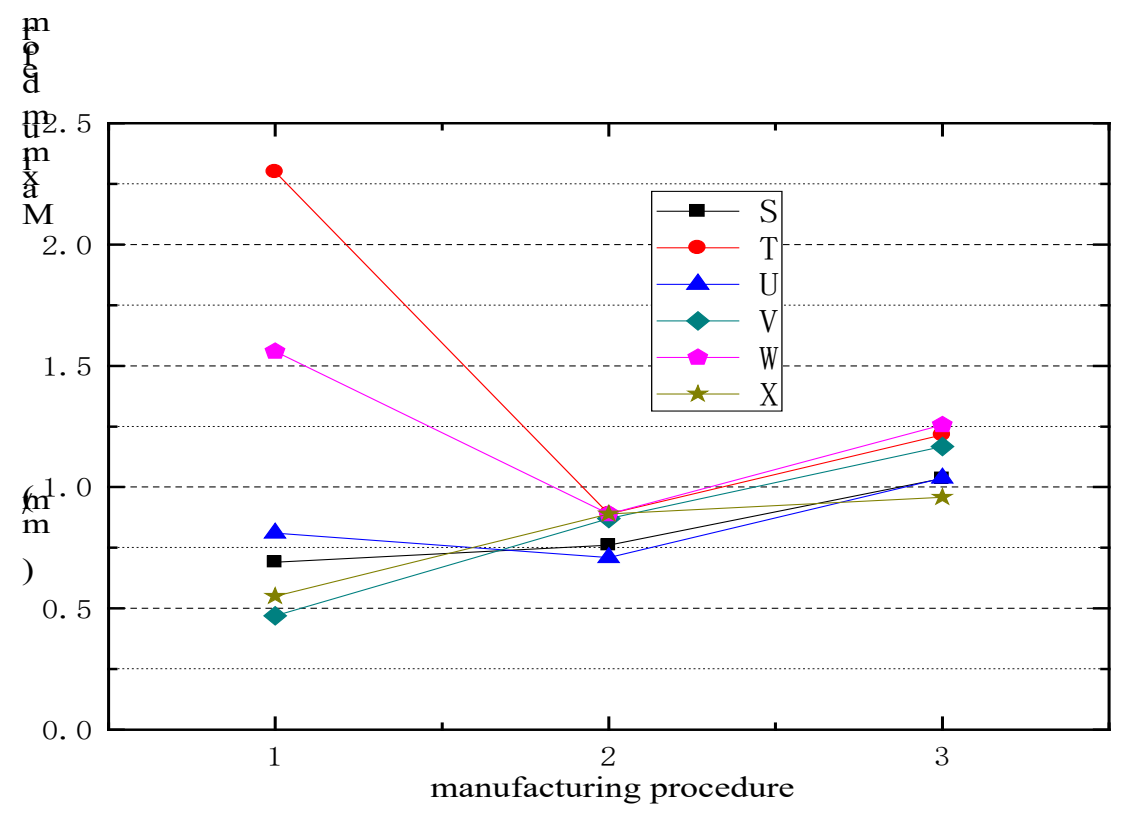

Figure 13: Maximum deformation of workpiece in different frame processing sequence

Figure 13 shows that the "T" and "W" removal methods are relatively large in the first step. whereas the "S", "U", "V" and "X" four compartment removal methods in the first step of the processing process deformation is relatively small. This is because the "T" and "W" frame are removed by removing the upper part of the box first, while the "S "," U "," V" and "X" frames are removed by removing the lower part of the frame first. The material removed from the lower region is relatively large and concentrated in the main deformation area. First remove the lower area, other areas of the workpiece can provide a relative support to slow down the deformation of the workpiece. then remove the upper region with relatively small deformation.

\section{CONCLUSION}

In this study, the paper analyzes the deformation problem of the structure parts of aviation integral frame caused by different processing technology sequence of spacer frame. Based on Abaqus, a finite element model of processing deformation caused by initial residual stress in frame whole structure was established. The deformation law of frame whole structure caused by initial residual stress of blank is analyzed. The influence of the processing sequence of different frame on the deformation of the whole structure of aviation frame was studied. The results show that when removing the frame material, the deformation of the workpiece can be slowed down by first removing the area with large deformation and relatively concentrated material. And symmetrical removal of the frame material can also slow the deformation of the workpiece.

\section{SOURCES OF FUNDING}

Projects supported by the National Natural Science Foundation of China (No. 51605037). 


\section{CONFLICT OF INTEREST}

None.

\section{ACKNOWLEDGMENT}

None.

\section{REFERENCES}

[1] S Masoudi, S Amini, E Saeidi, H Eslami-Chalander. Effect of machining-induced residual stress on the distortion of thin-walled parts[J]. International Journal of Advanced Manufacturing Technology, 2015, 76(14): 597-608.

[2] JT Wang, YK Zhang, JF Chen, J Y Zhou, MZ Ge, YL Lu, XL Li. Effects of laser shock peening on stress corrosion behavior of 7075 aluminum alloy laser welded joints. [J] Materials Science \& Engineering A, 2015, 647: 7-14.

[3] T Maeno, K Mori, R Yachi. Hot stamping of high-strength aluminium alloy aircraft parts using quick heating[J]. CIRP Annals-Manufacturing Technology, 2017, 66(1): 269-272.

[4] RJH Wanhill, GH, Bray. Chapter 2-Aerostructural Design and Its Application to Aluminum-Lithium Alloys[J]. Aluminum-lithium Alloys, 2014,14(7): 27-58.

[5] Huang X M, Sun J, Li J F. Finite element simulation and experimental investigation on the residual stressrelated monolithic component deformation[J]. The International Journal of Advanced Manufacturing Technology, 2015, 77(5/6/7/8): 1035-1041.

[6] S Nervi. A mathematical model for the estimation of effects of residual stresses in aluminum parts[D]. Washington: Washington University, 2005.

[7] Yuan W J, Wu Y X. Mechanism of Residual Stress Elimination for Aluminum Alloy Thick Plate Based on Prestretching Process[J]. Journal of Central South University (Natural Science Edition),2011,42(8): 23032308.

[8] F Zhang, Y Yan, SI Butt. Integrated model based thin-walled part machining precision control for the workpiece-fixture system [J]. International Journal of Advanced Manufacturing Technology, 2016, 85(5-8): 1745-1758.

[9] A Singh, A Agrawal. Investigation of surface residual stress distribution in deformation machining process for aluminum alloy[J]. Journal of Materials Processing Technology, 2015, 225: 195-202.

[10] X Jiang, Y Wang, Z Ding, H Li. An approach to predict the distortion of thin-walled parts affected by residual stress during the milling process[J]. International Journal of Advanced Manufacturing Technology, 2017, 93(9-12): 4203-4216.

[11] S Hossain, CE Truman, DJ Smith. Finite element validation of the deep hole drilling method for measuring residual stresses[J]. International Journal of Pressure Vessels and Piping, 2012, 93-94(5): 29-41. 